\title{
Kajian Teori Integral dalam Efektivitas Transformasi Kesadaran Lingkungan pada Bangunan Berkelanjutan
}

\author{
Anwar Subkiman \\ Jurusan Desain Interior, Fakultas Seni Rupa dan Desain, ITENAS, Bandung \\ Email: anwar.sub@itenas.ac.id
}

\begin{abstract}
ABSTRAK
Penerapan Prinsip Bangunan Hijau dimaksudkan untuk mewujudkan kehidupan yang lebih baik, terutama di kemudian hari. Lingkungan binaan yang diciptakannya mendorong kesejahteraan masyarakat yang dilingkupinya. Namun, perilaku desainnya baru semata penyelesaian teknis terhadap permasalahan krisis lingkungan yang tengah kita hadapi. Di sini, diperlukan juga peran perilaku manusianya yang juga berkesadaran lingkungan[1]. Perilaku desain, karena sifat teknisnya, cenderung akan mengalami kegagalan dalam masa penggunaannya. Untuk itu diperlukan kemantapan kesadaran lingkungan masyarakat untuk menjaga Perilaku Desain Hijau tetap berlangsung.

Peran desainer tidak hanya selesai pada solusi teknis tetapi juga hendaknya mempertimbangkan faktor manusianya untuk mencapai kesadaran terhadap lingkungan. Untuk mewujudkan tujuan ini, desainer dapat melakukan pendekatan dari empat perspektif Kuadran AQAL Teori Integral dengan Dinamika Spiral manusia sebagai aspek psikologisnya. Kuadran AQAL memetakan permasalah penerapan Desain Hijau dan menguraikan proses interaksi antara perilaku desain dengan perilaku kesadaran manusianya sebagai model stimulus - respon. Diharapkan proses argumentatif perilaku desain dalam mengintervensi kesadaran lingkungan masyarakat dapat tercapai secara efektif.
\end{abstract}

Kata kunci: Bangunan Hijau, Teori Integral, Dinamika Spiral, kesadaran lingkungan.

\begin{abstract}
Green Building Principles was applied to make we have a better life, especially in the future. Built enviroment that it created encourages well-being of its people. Design Behavior just solved the problem of enviroment crisis with the technical aspect. Also, we need role of human behavior with environmental consciousness. As technical aspect, Design Behavior has tend to failure operation. Therefore, the environmental consciousness people can be able to preserve Green Design Behavior.

The designer should be not only solve the problems with technical aspects but also consider human factors to achieve they environmental consciousness. To get this goal, designer can make approach with four perspectives of AQAL and Spiral Dynamics integral. AQAL maps the problems of Green Design applied then analyze the proses of interaction between Design Behavior and people consciousness behavior as stimulus - response model. We hope that Design Behavior can take a role to make argumentative proses to intervent people reach they environmental consciousness effectively.
\end{abstract}

Keywords: green building, Integral Theory, Spiral Dinamic, environmental consciousness. 


\section{PENDAHULUAN}

Dalam penciptaan lingkungan binaan, khususnya desain interior, interaksi antara desain dan manusia sangat erat dan saling timbal balik. Suasana ruang desain interior, secara langsung maupun tidak, akan mempengaruhi manusia di dalamnya. Sebagai contoh, suasana ruang yang terbuka dan berkesan lapang akan mempengaruhi perilaku manusia di dalamnya bekerja dengan pikiran yang lebih jernih dibandingkan mereka yang berada di ruang tertutup, suram, dan berantakan. Sebaliknya, kebutuhan manusia (sebagai design requirement) akan menentukan bagaimana desain dihasilkaryakan. Hubungan timbal balik ini diamini oleh psikologi lingkungan sebagai pendekatan partisipatif[2], di mana dalam proses perencanaan senantiasa memperhatikan aspek manusianya. Dalam psikologi lingkungan, di satu sisi, desain yang dirancang sedemikian rupa (selanjutnya kita sebut tampilan desain atau perilaku desain) menjadi stimulan bagi manusia di dalamnya (perilaku penghuni ruang). Di dalam desain interior, perilaku desain ini adalah suasana ruang sebagai behavior setting yang akan dimaknai oleh penghuni, baik secara denotatif maupun konitatif.

Dengan prinsip dasar di atas, premis bahwa desain interior yang hijau akan mempengaruhi perilaku manusia yang dilingkupinya menjadi berperilaku hijau pula. Jika penerangan desain interior dirancang menggunakan lampu LED yang menyala hanya jika ruang membutuhkannya (dengan lux sensor) dengan maksud menghemat energi sebagai salah satu Prinsip Desain Hijau, maka apakah penghuni di dalamnya akan serta merta memiliki perilaku hemat juga terhadap energi? Setiap individu memiliki ekspetasi berbeda-beda sehingga perilaku desain harus dapat melakukan proses argumentatif-nya dalam mengintervensi perilaku manusia[3]. Bahkan Behaviorisme memisahkan empat kondisi hubungan lingkungan dan perilaku sebagai berikut[4]:

- free-will approach: bahwa lingkungan tidak memberikan pengaruh sama sekali pada perilaku manusia.

- possibilistic approach: kecil pengaruh lingkungan pada perilaku manusia.

- probabilistic approach: perilaku manusia diberikan pilihan untuk mau atau tidak mengikuti pengaruh lingkungan.

- determinism approach: lingkungan membatasi perilaku manusia.

\section{METODOLOGI}

Banyak teori yang menjelaskan interaksi desain dengan manusia dalam kajian psikologi lingkungan dengan berbagai parameter, terutama pada proses stimulasi yang terjadi. Kesimpulan yang dapat ditarik dari teori tersebut yang dijadikan fokus penelitian ini yakni lebih menitikberatkan pada objek kajian (perilaku) manusianya. Interaksi diawali dengan kajian behaviorism dan Gestalt dengan menerapkan Teori Pembangkit (arousal), Teori Beban Stimulus, dan Teori Adaptasi[2]. Proses yang terjadi dalam diri manusia adalah: perilaku desain diterima sebagai stimulus oleh penghuni - proses kognisi penghuni melakukan persepsi terhadap stimulus - menghasilkan sikap/perilaku. Selanjutnya, penelitian dilanjutkan dengan kajian yang lebih tajam dengan Teori Integral yang diusung Ken Wilber. Teori ini menjadi alat efektif dan efisien yang dapat digunakan dalam mencapai tujuan desain dalam mempengaruhi penghuninya.

Penelitian ini mengambil kasus para pegawai yang bekerja di dalam kantor yang didesain dengan Prinsip Bangunan Berkelanjutan, salah satunya penerapan konsep pencahayaan ruang yang hemat energi. Dengan demikian, parameternya adalah: desain pencahayaan hemat energi sebagai tampilan desain atau perilaku desain - para pegawai sebagai penghuni - dan perilaku yang diinginkannya adalah kesadaran lingkungan (perilaku hemat energi) para penghuni kantor. Namun, sebagai data yang dikaji dalam Teori Integral tidak cukup hanya manusia dan desain yang melingkupinya. Menurut 
Wilber[5], ini baru setengah dari pembahasan. Diperlukan data lain agar Teori Integral dapat dipenuhi. Data yang dimaksud adalah seperti diurai dalam Bagian 3. Hasil dan Pembahasan.

\subsection{Teori Integral.}

Teori Integral adalah metode pengkajian dalam menyelesaikan segala masalah (sehingga teori ini juga disebut Theory of Everthing), dengan empat perspektif yang dipetakan dalam Empat Kuadran AQAL (All Quadrants All Levels). Teori ini dikemukan oleh Ken Wilber, seorang penulis psikologi evolusioner berkebangsaan Amerika. Teori Integral merupakan kritik terhadap teori psikologi yang selama ini, menurutnya terlalu pluralisistik. Sebuah teori memiliki kelebihan memecahkan masalah psikologi dari satu aspek tetapi tidak dapat menutupi dari aspek yang lainnya[5].

Teori Integral memetakan kajian ke dalam empat kuadaran (Gambar 1). Dua kuadran kanan adalah data yang bersifat objektif (eksterior) sedangkan dua kuadran kiri bersifat subyektif (interior). Tampilan gedung yang menerapkan Prinsip Bangunan Hijau menempati Kuadaran Kanan Atas (UR) sedangkan Prinsip Desain Bangunan sebagai sistem menempati Kuadran Kanan Bawah (LR) beserta sistem lainnya yang terkait. Pada Kuadran Kiri Atas (UL) adalah proses interaksi psikologis setiap penghuni (individu) yang memberikan pengalaman dan kesadaran lingkungan para penghuni (individual). Sedangkan pada Kuadran Kiri Bawah (LL), tampilan Bangunan Hijau memberi nilai baru pada budaya para penghuni secara kolektif. Kuadran AQAL ini mewakili proses perilaku (Kesadaran Hijau) pada diri manusia (individu-kolektif/subyektif-internal) dan perilaku Bangunan Hijau (bangunan-sistem/objektif-eksternal).

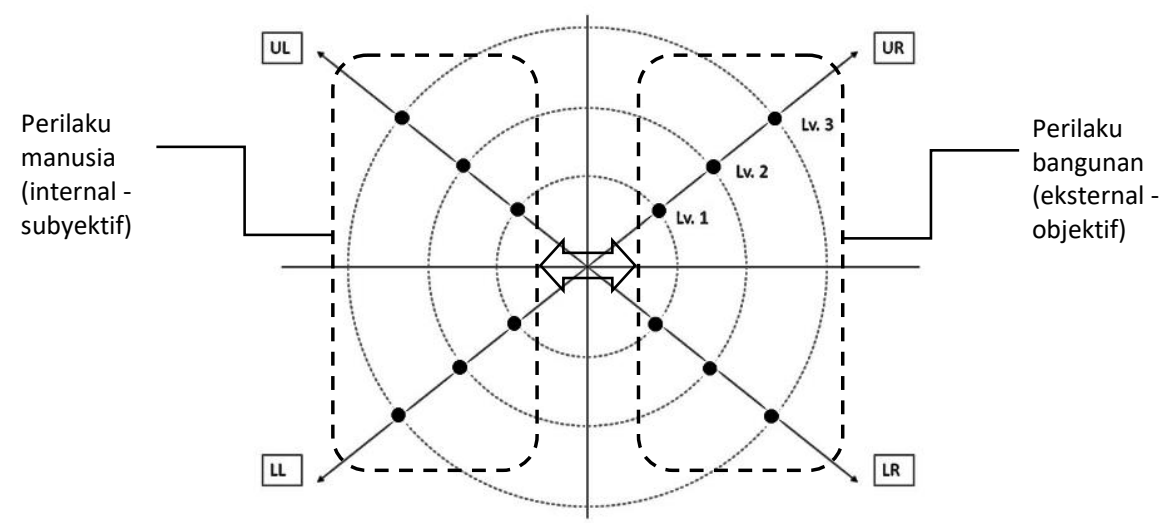

\section{Gambar 1. Kuadran AQAL dan hubungan proses perkembangan perilaku pada manusia terhadap bangunannya. Sumber: diadaptasi dari Welber[5]}

Kajian penelitian ini diawali dari Kuadran UR, yakni Perilaku Desain Hijau sebagai sebuah lingkungan binaan hasil karya desainer. Perilaku Desain ini diharapkan dapat memberikan pengalaman kepada dan mengintervensi para penghuni menuju ke kesadaran lingkungan pada Kuadran UL secara individu. Selanjutnya, kesadaran lingkungan kolektif pada Kuadaran LL adalah nilai yang didapat dari Perilaku Desain. Interaksi ini tidak cukup jika tanpa melibatkan sistem pada Kuadran LR.

Setiap kuadran memiliki tingkatan (level atau gelombang) perkembangan yang sudah atau akan dicapai. Gradasi level ini sebetulnya memiliki spektrum yang luas, namun pada kajian ini dibatasi pada tiga level saja. Ke dalam pemetaan masalah, maka level masing-masing kuadran ditunjukan oleh Gambar 2 berikut. Untuk mencapai level yang diinginkan, maka diperlukan model Dinamika Spiral 
Clare Graves[5], yakni setiap level akan memiliki gelombang yang akan saling mempengaruhi dan tumpang tindih dari level di kuadran satu ke level kuadran lainnya.

Meminjam model Teori Integral pada Bangunan Berkelanjutan Mark Dekay, maka apa yang sudah dilakukan oleh bangunan dalam menerapkan Prinsip Bangunan Hijau baru sebatas pada kuadran UR objektif eksternal, yakni perspektif teknis yang kemudian kita sebut sebagai Perilaku Bangunan Hijau[6]. Kembali kepada interaksi lingkungan binaan dan manusia yang dilingkupinya, maka dalam Kuadran AQAL, interaksi yang terjadi adalah antara Kuadaran Wilayah Kanan dan Kiri. Kuadaran AQAL memberikan gambaran efektif bagaimana interaksi tersebut akan terjadi. Memberikan pemetaan potensi kesadaran manusia untuk di-intervensi oleh Perilaku Bangunan sesuai dengan tujuan desain yaitu Kesadaran Lingkungan sebagai tujuan Prinsip Bangunan Hijau. Kuadran Wilayah Kanan, sisi teknikal, mempunyai kemungkinan kuat untuk sewaktu-waktu tidak berfungsi atau rusak. Sedangkan Kuadran Kiri memerlukan waktu dalam proses pembelajarannya, namun dalam pencapaiannya akan menjadi kesadaran yang kuat sehingga mampu untuk menjaga Perilaku Bangunan tetap berlangsung sesuai fungsinya.

\section{Gambar 2. Tabel pemetaan level permasalahan pada setiap Kuadran AQAL.}

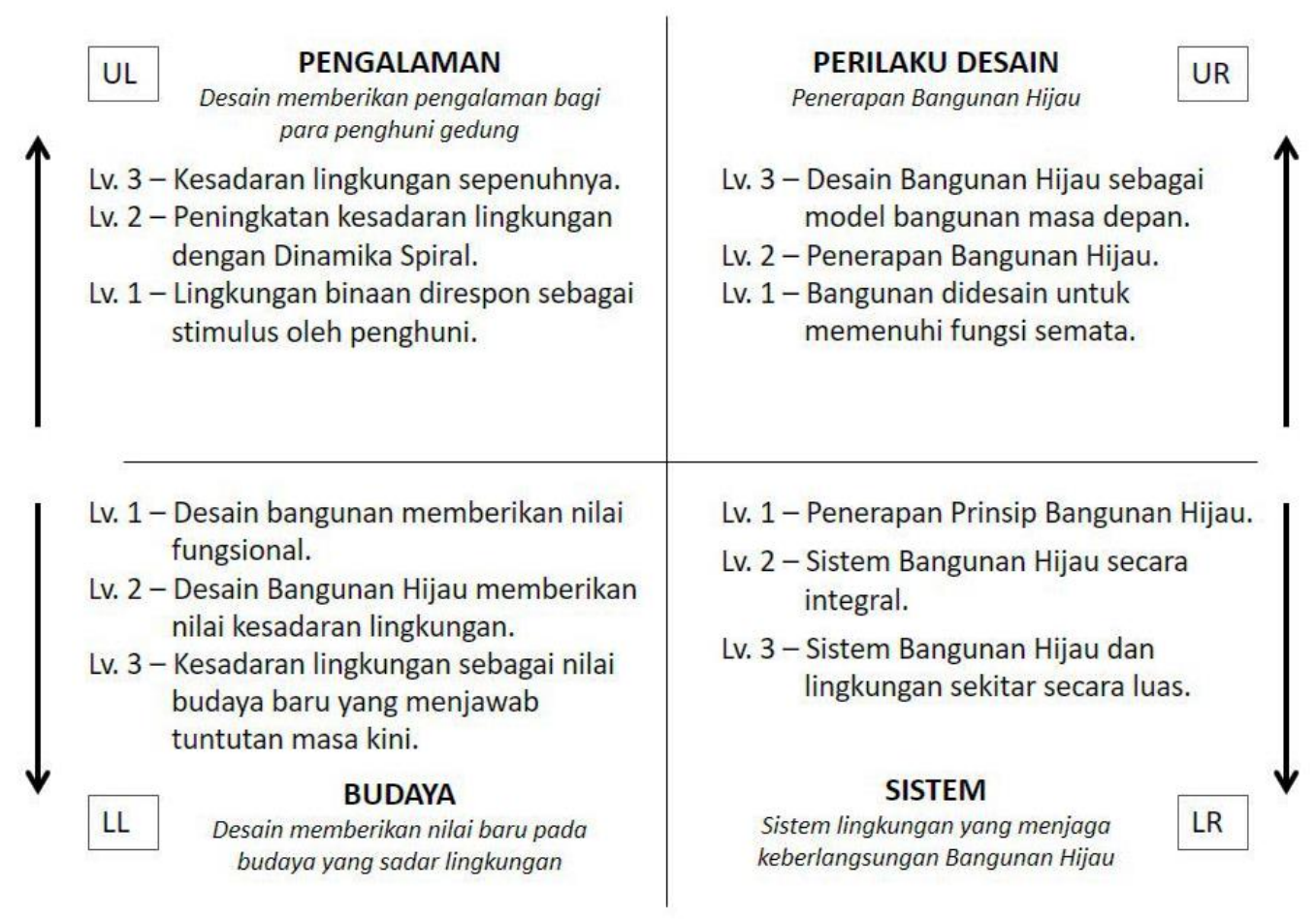

Hal tersebut selaras dengan kredo Bangunan Berkelanjutan bahwa desainer adalah agen perubahan. Desainer dengan karyanya mempunyai tugas mengubah paradigma masyarakat ke arah yang lebih baik. Jika sebelumnya, dalam arsitektur terjadi dialog antara seni (estetika) dan teknologi (fungsi), maka kondisi terkini adalah waktunya dilakukan dialog antara teknologi dan lingkungan. Para desainer mengeban tugas menciptakan desain yang ramah lingkungan, Desain Hijau, Desain Berkelanjutan. Untuk itu, tugas desainer seharusnya tuntas, tidak saja selesai pada proses desain, pengawasan pelaksanaan agar desain dibangun sesuai perencanaan, tetapi juga memikirkan sistem yang menjaga desain dapat berfungsi sebagaimanamestinya dan berkesinambungan. 


\subsection{Dinamika Spiral.}

Teori Integral Ken Wilber tidak bisa terlepas dari Proyek Kesadaran Manusia yang dilakukan oleh Clare Graves (Wilber, 2012, hal. 18). Graves melakukan penelitian menyeluruh yang memetakan psikologi manusia secara global, menyeluruh, dan lintas budaya. Penelitian Graves kemudian dikembangkan oleh Don Beck dan Christopher Cowan yang memetakan kesadaran manusia ke dalam tahapan yang kemudian dikenal dengan Dinamika Spiral. Pendekatan Dinamika Spiral ini adalah komponen psikologis dalam Teori Integral. Interaksi antara Kuadran UL (subyektif-individu) dengan kuadran lainnya berlangsung dengan pendekatan ini.

Dinamika Spiral ini meninggalkan teori Marslow yang popular sebelumnya. Beck dan Cowan membagi manusia ke dalam beberapa tahap yang sebut dengan meme. Meme adalah sifat atau kesadaran yang dimiliki setiap individu yang terekspresikan dalam aktivitasnya. Bisa jadi meme adalah hasil proses kognitif komprehensif dalam diri setiap individu dalam merespon stimulan sekelilingnya dalam teori behavioristik. Meme bersifat melekat tetapi dapat berubah (dinamis) dari tahap lebih rendah ke tahap berikutnya. Namun menariknya, meme di satu tahap tidak pernah melupakan meme di bawahnya, bahkan merangkulnya (seperti pusaran spiral)! Beck\&Cowan membagi ke dalam delapan tahap meme yang dapat dicapai manusia. Dua tahap awal adalah kesadaran fundamental dan terjadi pada manusia atau masyarakat primitif. Sedangkan tahap terakhir adalah capaian paripurna. Setiap meme diberi warna sebagai ciri. Dari beberapa penelitian mereka bahkan mendapatkan komposisi populasi dan peta kekuatannya dalam sebuah kelompok masyarakat serta menjamin bahwa komposisi ini berlaku di setiap kelompok masyarakat di mana pun berada. Walaupun tidak persis, populasi dan kekuatan kelompok meme ini juga terbukti pada para pegawai di lingkungan Gedung KAMPUS PT Dahana Subang, bangunan yang memiliki sertifikat Bangunan Hijau dari Green Building Council Indonesia (GBCI) yang menjadi objek kajian penelitian ini (lihat Tabel 1).

Tabel 1. Tahapan kesadaran manusia Beck\&Cowan[5] dan data populasi pegawai Gd. Kampus PT Dahana [7].

\begin{tabular}{|c|c|c|c|c|c|}
\hline Tahap & Meтe & Kesadaran & Populasi & Kekuatan & $\begin{array}{l}\text { Populasi Peg } \\
\text { Gd. KAMPUS } \\
\text { PT Dahana } \\
\end{array}$ \\
\hline 9 & $\begin{array}{l}\text { Meme Koral } \\
\text { HOLONIC - integral holonik }\end{array}$ & relational & - & - & \\
\hline 8 & $\begin{array}{l}\text { Meme Pirus } \\
\text { HOLISTIC - pandangan } \\
\text { menyeluruh }\end{array}$ & $\begin{array}{l}\text { transperson } \\
\text { al }\end{array}$ & $0,1 \%$ & $1 \%$ & \\
\hline 7 & $\begin{array}{l}\text { Meme Kuning } \\
\text { INTEGRAL - fleksibel, } \\
\text { spontan, fungsional }\end{array}$ & $\begin{array}{l}\text { kompleksita } \\
\text { s dinamis }\end{array}$ & $1 \%$ & $5 \%$ & \\
\hline 6 & $\begin{array}{l}\text { Meme Hijau } \\
\text { PLURALISTIK - kepekaan, } \\
\text { perasaan, kepedulian }\end{array}$ & egalitarian & $10 \%$ & $15 \%$ & $22-25 \%$ \\
\hline 5 & $\begin{array}{l}\text { Meme Jingga } \\
\text { SCIENTIFIC - pencerahan }\end{array}$ & $\begin{array}{l}\text { achievement } \\
\text { oriented }\end{array}$ & $30 \%$ & $50 \%$ & \\
\hline 4 & $\begin{array}{l}\text { Meme Biru } \\
\text { MYTHIC - kekuatan kebenaran }\end{array}$ & conformist & $40 \%$ & $30 \%$ & \\
\hline 3 & $\begin{array}{l}\text { Meme Merah } \\
\text { POWER GODS - dewa-dewi } \\
\text { kekuatan }\end{array}$ & ethnocentric & $20 \%$ & $5 \%$ & $13 \%$ \\
\hline 2 & $\begin{array}{l}\text { Meme Ungu } \\
\text { MAGICAL - semangat } \\
\text { persaudaraan }\end{array}$ & egocentric & $10 \%$ & $1 \%$ & \\
\hline
\end{tabular}




\begin{tabular}{|c|l|c|c|c|c|}
\hline Tahap & \multicolumn{1}{|c|}{ M e m e } & Kesadaran & Populasi & Kekuatan & $\begin{array}{c}\text { Populasi Peg } \\
\text { Gd. KAMPUS } \\
\text { PT Dahana }\end{array}$ \\
\hline 1 & $\begin{array}{l}\text { Meme Beige } \\
\text { ARCHAIC - fundamental }\end{array}$ & impulsive & $0,1 \%$ & 0 & \\
\hline
\end{tabular}

Kajian penelitian ini akan lebih menyentuh area meme merah hingga hijau. Meme hijau adalah ekspatasi yang hendak dicapai sang agen perubahan. Meme merah akan mudah untuk dipaksa berubah sedangkan meme jingga dan biru memiliki potensi kuat (dengan jumlah populasinya serta kesadaran yang dimiliknya) untuk diintervensi deangan paradigma baru, Perilaku Hijau. Seperti telah disebutkan sebelumnya dua tahapan meme awal dapat diabaikan karena populasinya nyaris sudah tidak ada dan tanpa kekuatan. Tiga meme paling tinggi hanya dimiliki oleh individu yang paripurna dengan tingkat kesadaran yang tinggi (being level).

Mengapa tahap kesadaran meme hijau? Meme hijau adalah jiwa yang peka. Memiliki sikap yang mendahulukan kesetaraan dibanding hirarki. Dia sangat peduli dengan lingkungan dan memiliki tenggaang rasa. Dia diyakini dapat menyusun harmoni. Tahap inilah yang cocok bagi sang agen perubahan Bangunan Hijau yang ramah lingkungan[5].

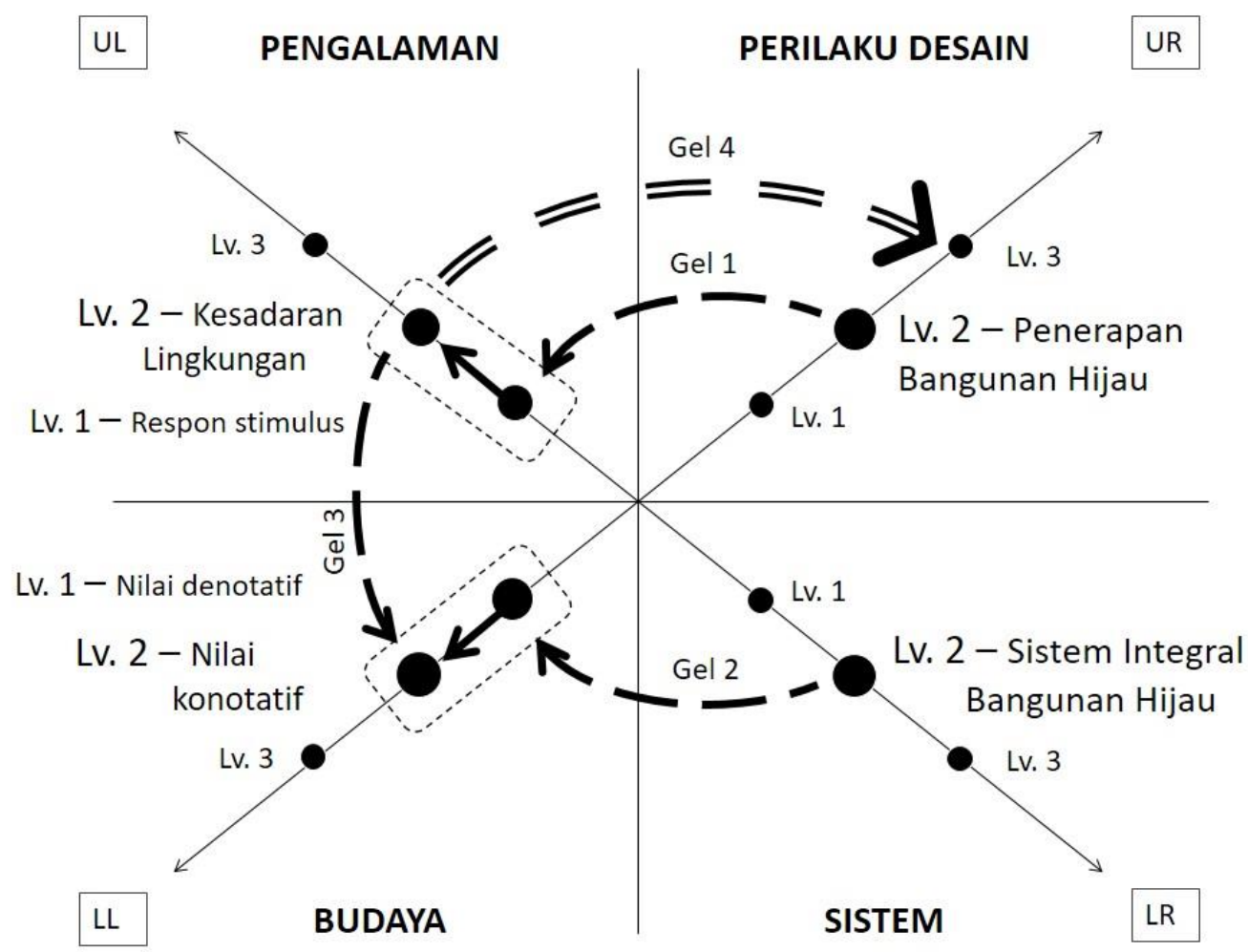

Gambar 3. Gelombang interaksi antarlevel dan antarkuadran. Sumber: adaptasi dari DeKay[6].

Menggabungkan Teori Integral dan Dinamika Spiral, kajian ini berawal dari status Perilaku Desain Level 2 yang akan memberikan pengaruh gelombang kesadaran di wilayah kuadran lainnya, terutama Kuadran Subyektif, UL dan LL. Gelombang pertama (Gel. 1) terjadi dari Perilaku Desain menjadi 
stimulus bagi penghuni memberikan pengalaman (Lv. 1 - Kuadran UL) baru yang diharapkan meningkat ke kesadaran lingkungan (Lv.2), lihat diagram Gambar 3. Peningkatan kesadaan individu ini (Kuadran UL) akan mempengaruhi peningkatan level pemaknaan di Kuadran LL(Gel. 3). Peningkatan kesadaran ini juga memerlukan integrasi perkuatan dari sistem Lv. 2 Kuadran LR (Gel.2). Pada akhirnya capai Lv.2 Kuadran UL dan Lv.2 Kuadran LL akan menimbulkan gelombang baru (Gel. 4) yang akan meningkatan level Perilaku Desain ke Lv. 3. Demikan seterusnya seolah gelombang yang tidak ada henti.

\section{HASIL DAN PEMBAHASAN}

\subsection{Kuadran UR - Perilaku Desain Hijau.}

Pemetaan Kuadran AQAL pada kajian ini diawali pada Penerapan Prinsip Bangunan Hijau berada di Kuadran UR (objektif/eksternal individual) sebagai Perilaku Desain yang telah dilakukan oleh desainer. Lengkapnya, pemetaan level telah digambarkan pada bagan Gambar 2. Kuadran ini sebagai wilayah obyektif, Perilaku Desain dimaksudkan untuk meningkatkan kualitas performa bangunan semata. Performa atau perilaku Desain Hijau yang diekspresikan dalam setiap elemen desainnya memberikan manfaat bagi bangunan itu sendiri sebagai usaha penghematan energi dan mengurangi dampak pada lingkungan.

Dari beberapa data dan contoh Bangunan Hijau di Indonesia telah terbukti bagaimana mereka dapat mengurangi konsumsi energi bangunan secara signifikan sesuai yang disyaratkan. Seperti Gedung KAMPUS PT Dahana dapat mengurangi penggunaan energi sebesar 30\% atau hanya 126,08 $\mathrm{kwh} / \mathrm{m}^{2} /$ tahun saja, bahkan jika dibandingkan rata-rata bangunan perkantoran pada umumnya, 250 $\mathrm{kwh} / \mathrm{m}^{2}$. Selain itu, kesehatan dan kinerja para karyawan menjadi meningkat serta efektif dan efisien dalam bekerja[7]. Sampai di sini, tugas Kuadran UR sudah selesai.

Agar memberikan gelombang yang dapat mempengaruhi kesadaran para penghuni, ekspresi Desain Hijau pada elemen bangunan harus dapat ditangkap dengan baik oleh setiap individu. Psikologi lingkugan menyarankan pembangkitan kesadaran dengan melakukan perkuatan stimulus dan berulangulang. Beberapa contoh penerapan Bangunan Hijau pada Gedung KAMPUS PT Dahana adalah sebagai berikut belum dimaknai oleh para pegawai sesuai dengan tujuan Desain Hijau dibuat. Pada Kuadran UL ini, elemen desain dicerap untuk memberikan pengalaman yang selanjutnya menjadi modal menjadi kesadaran lingkungan. Tugas terberat sang agen perubahan adalah menciptakan gelombang yang kuat dari elemen Desain Hijau yang dirancangnya sehingga dicerap seutuhnya oleh penghuni gedung. 


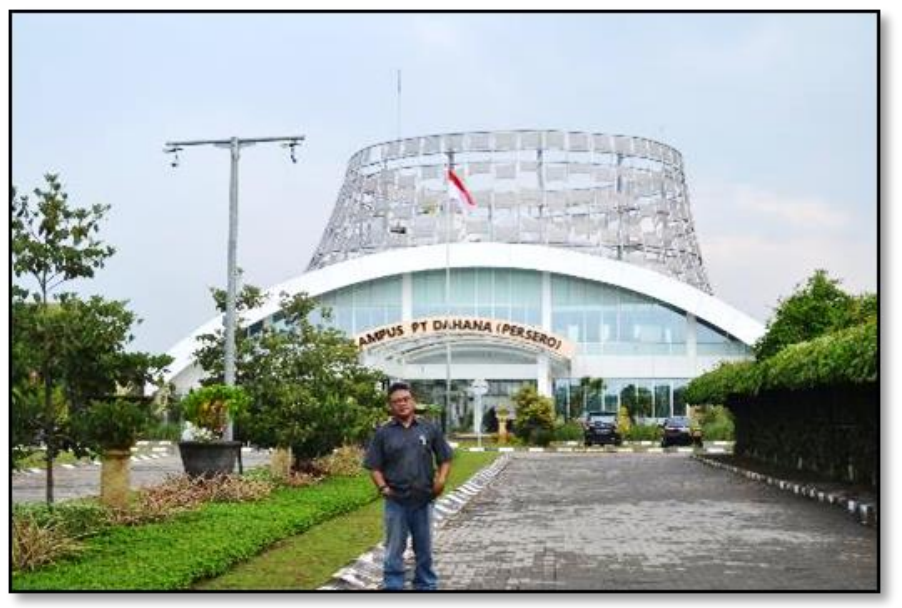

\section{Gambar 4. Gedung KAMPUS PT Dahana yang menerapkan Prinsip Banguan Hijau dan mendapatkan rating Platinum dari Green Building Council Indonesia.}

\section{Tabel 2. Contoh Penerapan Prinsip Bangunan Hijau pada Gedung KAMPUS PT Dahana [7].}

1. Penghematan energi - mengurangi konsumsi listrik penerangan dalam.

- Argumen desain: memanfaatkan cahaya siang.

- Elemen desain: bentuk bangunan yang ramping dengan jendela lebar pada kedua sisi, penggunaan kaca low-E, lampu LED, lux sensor.
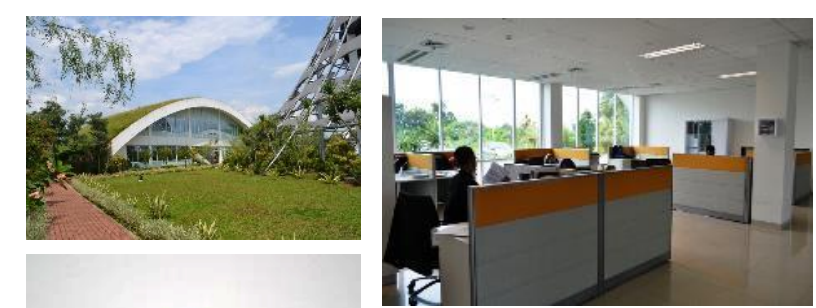

2. Mengurangi dampak pada lingkungan.

- Argumen desain: penggunaan AC yang ramah lingkunngan.

- Elemen desain: selubung bangunan (secondary skin), green roof, watter cooling system, recycle air limbah.
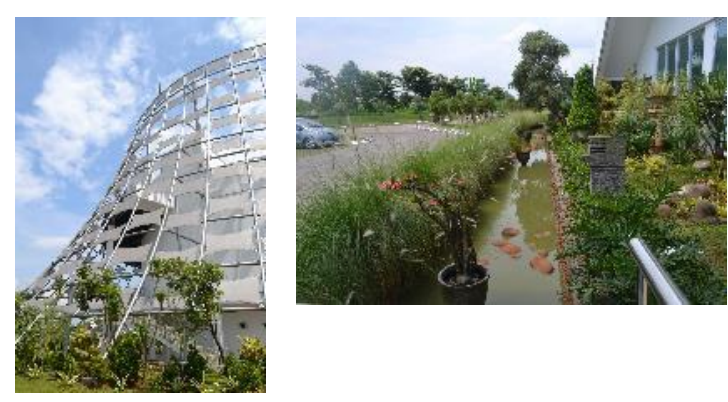


\subsection{Kuadran UL - Pengalaman Penghuni Gedung.}

Gelombang stimulus dari elemen Perilaku Desain memang memerlukan waktu agar dicerap sempurna oleh penghuni. Apalgi sejauh ini, diakui bahwa Bangunan Hijau belum diwakili oleh ikon estetika tertentu sebagaimana gaya bangunan sebelumnya. Kita sekarang mudah mengenali gaya modernisme, post-modernisme, hingga faham dekonstruksi. Namun kita belum merumuskan seperti apa tampilan Bangunan Hijau - tentu saja tidak sekedar warna hijau! Oleh karena itu, hanya mengandalkan apa yang dilihat oleh penghuni bisa jadi ia tidak sadar berada dalam lingkungan binaan yang telah ramah lingkungan. Namun paling tidak proses respon terhadap stimulus tersebut berjalan benar. Eleman Desain Hijau pada Gedung Hijau memberikan pengalaman baru dalam perilaku bekerja sehariharinya. Seperti dua Prinsip Bangunan Hijau yang diuraikan pada Tabel 2 direspon oleh para pegawai dan menjadi pengalaman baru, bahwa:

- Cahaya siang yang masuk lewat jendela lebar disadari cukup menerangi area kerja tanpa harus menggunakan penerangan buatan.

- Jendela lebar memberikan pandangan yang luas dan dinamis ke luar bangunan dapat mengurangi stress kerja[8].

- Penggunaan lux sensor yang menghidupkan dan mematikan penerangan buatan berdasarkan intensitas cahaya siang yang masuk membantu perilaku gedung dalam mengurangi konsumsi energi listrik secara efektif.

- Pengkondisian udara (AC) yang lebih stabil (temperatur dan debit udara) dari water cooling system dibandingkan sistem konvensional (yang menggunakan pendingin refrigeran) menyadarkan para pegawai terhadap pilihan lain pengkondisian udara yang ramah lingkungan. Ditambah wawasn bahwa air yang digunakan untuk mendinginkan AC menggunakan air daur ulang.

- Desain atap hijau (green roof) sangat membantu meredam panas siang masuk ke dalam bangunan selain ketika hujan berfungsi pula sebagai penangkap air hujan untuk kebutuhan rain water harvesting.

- dst.

Dinamika Spiral memberikan harapan optimis pada para desainer bahwa mereka tetap dapat mengintervensi desainnya kepada para penghuni. Dengan Dinamika Spiral, Perilaku Desain dapat memanfaatkan peran argumentatifnya. Pengalaman para pegawai ini akan mempengaruhi respon kognitifnya menjadi pengetahuan dan wawasan baru baginya. Dengan dominasi populasi meme biru (kesadaran konformis) dan jingga (kesadaran achievement oriented) seperti telah diuraikan di Bagian 2 sebelumnya, maka para pegawai siap untuk melangkah ke meme di atasnya, menjadi egalitarian meme hijau.

\subsection{Kuadran LR - Sistem Lingkungan Berkelanjutan.}

Kuadran LR ini, sebagai suatu sistem yang berkembang dari tahap paling kecil elemen Bangunan Hijau hingga meluas, menjangkau wilayah di luar bangunan, dapat dimanfaatkan dalam memberikan perkuatan stimulus di Kuadran UL. Penerapan Bangunan Hijau sendiri sudah menjadi sistem pada Level 1 Kuadran LR. Kemudian masing-masing elemen Bangunan Hijau tersebut tentu saja tidak dapat berdiri sendiri melainkan berada dalam satu kesatuan yang integral. Misal, di area kerja Gedung KAMPUS PT Dahana, penerapan penggunaan pengkondisian udara (AC) yang menggunakan water cooling tower system tidak akan berhasil tanpa usaha dari pengurangan panas lampu penerangan hasil dari penerapan lux sensor. Sistem AC ini pun juga memerlukan air daur ulang. Panas iklim lingkungan juga sudah diredam oleh green roof atau atap hijau sehingga tidak meningkatkan temperatur ruang. Ringkasnya, Gedung KAMPUS PT Dahana sebagai sebuah sistem yang bersifat teknis di Level 2 telah berhasil mengurangi ketergantungan konsumsi energi buatan serta dampak terhadap perusakan lingkungan. 
Di level ini, diperlukan juga sistem yang berupa aturan, kebijakan, himbauan yang bertugas menginformasikan Perilaku Desain Hijau, menjaganya sehingga tujuan Prinsip Bangunan Hijau dapat tercapai secara efektif. Sistem non-teknis ini yang tidak kalah pentingnya memberikan gelombang kesadaran kepada individu di Kuadran UL. Sepeti halnya Al Gore tidak akan mencapai tujuannya dalam memperingatkan umat manusia tentang krisis lingkungan yang tengah mengancam tanpa berkeliling dunia mempresentasikan berbagai fakta kerusakan alam tersebut[9].

Pada kasus Gedung KAMPUS PT Dahana, bahwa perolehan sertifikasi Bangunan Hijau dari GBCI adalah sistem non-teknis yang dimaksud. Ditambah dengan banyak penghargaan dari berbagai institusi membuat para pegawai semakin berbangga. Dan tentu saja meyadarkan bahwa kebanggaan itu berawal dari Perilaku Desain Bangunan Hijau. Ini lah yang dimaksud dengan perkuatan gelombang intervensi Sistem terhadap perilaku manuisa dalam koridor model stimulus - respon. Hubungan Sistem dan perilaku penghuni dalam kondisi determinism approach.

Pihak manajemen perusahaan pun memberikan aturan ketat yang mendukung perilaku Hijau yang diberlakukan di area bangunan. Contohnya adalah larangan merokok! Sistem non-teknis ini dinilai penting dan benar adanya jika dibandingkan dengan apa yang terjadi pada Gedung Sampoerna Strategic Square Jakarta. Gedung Sampoerna juga memperoleh sertifikasi dari GBCI namun tidak didukung dengan kebijakan yang ketat dalam mendukung perilaku Hijau bagi para tenant-nya sehingga Perilaku Desain tidak menjadi stimulus yang diharapkan (possibilistic approach). Demikian juga yang terjadi pada Grha Wiksa Praniti Kementerian PU di Bandung yang tidak mendapat sertifikasi dari lembaga semacam GBCI. Para pengunjung nyaris sama sekali tidak mengetahui bahwa gedung tersebut dirancang dengan Prinsip Bangunan Hijau (free-will approach).
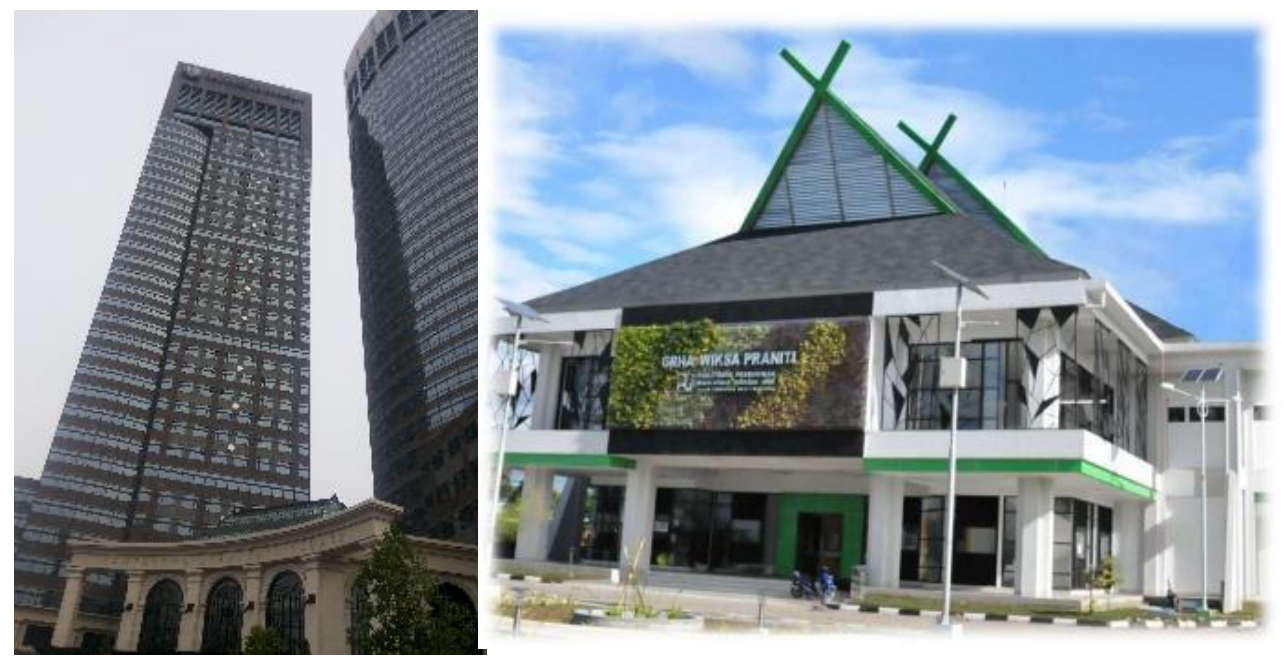

\section{Gambar 5. Gedung Sampoerna Strategic Square Jakarta dan Grha Wiksa Praniti Bandung [10].}

\subsection{Kuadran LL - Budaya Kesadaraan Lingkungan.}

Peningkatan ke Level 2 di Kuadran UL akan mempengaruhi level di Kuadran LL. Level 1 Kuadran UL yang sekedar respon inderawi dari stimulus Perilaku Desain setara dengan pemaknaan denotatif semata di Level 1 Kuadran LL ini. Seiring dengan perkembangan kesadaran Kuadran UL, maka Perilaku Desain sampai pada pemaknaan konotatif menjadi budaya baru. Dari Perilaku Desain Hijau ke Budaya Hijau yang bersifat kolektif. Seperti telah disebutkan di awal bahwa kedua kuadran subyektif ini, terutama Kuadran LL akan menjamin keberlangsungan Perilaku Desain tetap berjalan. 


\section{SIMPULAN}

Dari aspek teknis bahwa penerapan Prinsip Bangunan Hijau telah jelas menyodorkan manfaat yang tidak hanya menyelesaikan krisis lingkungan yang tengah kita hadapi tetapi terbukti dapat meningkatkan performa bangunan dan juga kesejahteraan penghuninya. Namun, aspek teknis memiliki kecenderugan sewaktu-waktu dapat rusak sehingga memerlukan peran lain untuk menjaga dan merawatnya agar tetap berfungi. Peran ini ada pada faktor manusia sebagai penghuni yang juga seharusnya memiliki kesadaran lingkungan yang selaras deangan Perilaku Desain Hijau. Agar interaksi Perilaku Desain dengan perilaku manusia berjalan efektif, para desainer dapat memanfaatkan Kuadran AQAL dalam menumbuhkan kesadaran lingkungan ini. Tahapan meme pada Dinamika Spiral menjadi pemetaan potensi intervensi desain pada perilaku manusianya.

Hal penting juga disimpulkan dari penelitian ini adalah adanya perkuatan Sistem pada Level 2 Kuadran LR. Bahwa usaha desainer dalam menerapkan Prinsip Bangunan Hijau harus dideklarasikan dan didengungkan kepada para penghuni agar dapat stimulus yang diekspresikan desain dapat direspon secara lanngsung. Jika diperlukan, pengelola gedung dapat membuat aturan yang ketat dan bersifat mengikat (determinism approach).

Interaksi Perilaku Desain dan perilaku manusia penghuni gedung sebagai pertimbangan faktor manusiwi agar dapat terjadi pada semua bangunan yang menerapkan Prinsip Bangunan Hijau. Kita tidak berharap bahwa desain yang dihasilkaryakan tidak sekedar menjadi monumen tanpa jiwa kesadaran lingkungan. Di Indonesia, setiap tahunnya sudah bertambah bangunan hijau yang disertifikasi GBCI. Semoga usaha kita menciptakan kehidupan yang lebih baik di kemudian hari dapat tercapai.

\section{UCAPAN TERIMA KASIH}

Artikel ini adalah buah beberapa rangkaian penelitian yang dilakukan penulis sejak tesis hingga penelitian yang dibiayai oleh LP2M Itenas, maupun penelitian mandiri. Untuk itu, penulis mengucapkan terima kasih kepada semua pihak telah memberikan membantu penulis melakukan penelitian ini. Tidak lupa juga kepada para reviewer serta kolega di Jurusan Desain Interior ITENAS atas masukan yang sangat bermanfaat.

\section{DAFTAR PUSTAKA}

[1] Papanek, Victor. (1955). The Green Imperative. Ecology and Ethics in Design and Architecture. London: Thames and Hudson.

[2] Iskandar, Tb. Zulrizka. (2013). Psikologi Lingkungan. Metode dan Aplikasi. Bandung: PT Refika Aditama.

[3] Hidjaz, Taufan. (2015). Mengkaji Kreatuvitas Mencapai Makna Baru Desain Interior. Bandung: Jurusan Desain Interior Itenas.

[4] Lang, Jon. (1987). Creating Architectural Theory. The Role of the Behavioral Sciences in Environment Design. New York: Van Nostrand Reinhold Co.

[5] Wilber, Ken. terj. (2012). A Theory of Everything. Solusi Menyeluruh atas Masalah-masalah Kemanusiaan. Jakarta: Mizan Publika.

[6] DeKay, Mark. (2011). Integral Sustainable Design. Transformative Perspectives. New York: Earthscan. 
[7] Subkiman, Anwar. (2014) Tesis: Kajian Pengaruh Pemanfaatan Pencahayaan Siang pada Interior Kantor Gedung KAMPUS PT Dahana terhadap Kesadaran Lingkungan Pegawainya sebagai Strategi Penerapan Bangunan Berkelanjutan. Bandung: FSRD ITB.

[8] ___ (2016). Kajian Solusi Desain Interior terhadap Pencahayaan Siang Berlebih pada Bukaan Jendela Lebar Bangunan Berkelanjutan. Prosiding Seminar Nasional Itenas 2016. Peranan Rekayasa dan Desain dalam Percepatan Pembangunan Nasional Berkelanjutan. hal 36 - 46. Bandung: LP2M Itenas.

[9] Al Gore. terj. (2010) Our Choice. Rencana untuk Memecahkan Krisis Iklim. Yogyakarta: Kanisius.

[10] www.eproduklitbang,pu.go.id/green-building/300617 diakses Mei 2017 